\title{
Transformation Plasticity and Toughening
}

G.B. Olson

Northwestern University, Department of Materials Science and Engineering, 2225 North Campus Drive, Evanston, IL 60208-3108, U.S.A.

\begin{abstract}
Analysis of the dynamic evolution of multilevel structure during martensitic transformations provides kinetics-based constitutive relations for transformation plasticity. Application in numerical modeling of ductile fracture by microvoid-softening-induced shear localization, in conjunction with metallographic study of crack-tip processes, identifies transformation toughening mechanisms operating on three structural length scales. Dispersedphase transformation toughening in ultrahigh-strength martensitic steels demonstrates record levels of fracture toughness.
\end{abstract}

\section{INTRODUCTION}

The operation of structural transformation as a deformation mechanism occurs widely throughout materials. By far the most studied prototypical case is the transformation plasticity associated with martensitic transformations, an area of intense recent interest stimulated by the achievement of high fracture toughness levels in both metals and ceramics. Developing a broad view of transformation plasticity and toughening phenomena, a research program over the past decade has addressed these phenomena in high-strength materials based on both homogeneous and dispersed-phase systems and involving toughening interactions with both ductile and brittle failure mechanisms. Concepts evolving from this research have played an important role in the multi-institutional Steel Research Group (SRG) program [1] focused on the fundamental principles allowing design of new classes of advanced steels with high toughness and ductility, which has in turn allowed the development of an undergraduate course on Materials Design [2,3]. This overview summarizes recent progress in this research, with special emphasis on toughening in ductile solids.

\section{DYNAMIC HIERARCHICAL STRUCTURE}

The late C. S. Smith [4] expounded on the universal hierarchical nature of material structure, emphasizing multilevel interactions and the intrinsic dynamic path-dependent nature of all structure. To apply this complex view, Smith recommended a "systems approach" to materials, which we have developed in our research and teaching in materials design.

The system flow-block diagram of Figure 1 presents an overview of dynamic hierarchy in displacive transformations. The blocks at the left denote unit microstructural subsystems of varying length scales, 
while the longer blocks at the right denote a sequence of unit processes each interacting with a range of microstructural levels, moving toward higher scales in both space and time. As denoted by the connections in Figure 1, initial nucleation events are sensitive to interfacial defect structures, while dislocation substructure development plays an important role in both the unit growth events producing product subunits and the autocatalytic nucleation resulting from these events. Solute interactions with interfacial mobility influence all levels of development including the highest scale of interactive growth of multivariant product groups.

The essential theoretical understanding of this dynamic system has been reviewed by Olson and Cohen [5]. Recent research in metals and ceramics has quantified the nucleation site potency distributions governing initial and autocatalytic nucleation in both nonthermoelastic [6,7] and thermoelastic [8] systems. This provides the framework for prediction of constitutive behavior associated with transformation under stress.

\section{TRANSFORMATION PLASTICITY}

As denoted by the stress-temperature diagram of Figure 2 [9], there are two modes of interaction of deformation with transformation termed (a) stress-assisted transformation in which applied stress assists the operation of the same nucleation sites controlling transformation on cooling, and (b) strain-induced transformation controlled by the production of new nucleation sites with plastic strain. A convenient measure of overall stability with respect to mechanically-induced transformation is the $\mathrm{M}_{\mathrm{s}}^{\sigma}$ temperature, below which stress-assisted transformation controls yielding. Due to the transformation dilation, this temperature is stress-state dependent.

\subsection{Stress-Assisted Transformation}

Constitutive relations derived by applying the calculated thermodynamic contribution of stress to previously-derived models for the kinetics of martensitic transformation on cooling are reviewed in Ref. [10]. The temperature dependence of the flow stress is influenced by both the transformation chemical thermodynamics and the interfacial mobility. The former also provides a pressure dependence, while the latter controls rate dependence. After an upper yield point determined by the potency of pre-existing nucleation sites, flow proceeds at a characteristic stress governed by autocatalytic nucleation, until sitesaturation causes rapid hardening.

Olson, Tsuzaki and Cohen [11] further extended this theoretical approach by calculating the manner in which the nucleation site potency distribution is effectively broadened by application of stress to a randomly oriented distribution of nucleation sites. The resulting statistical model accounts for previously unexplained nonlinear interactions of stress with transformation, and provides a smooth transformation yield locus for multiaxial stress. Application of the distribution model to dispersed-phase systems where pre-existing nucleation sites dominate behavior predicts smooth stress-strain curves as described in Ref. [10]. The recently determined autocatalytic potency distributions define the complete stress-assisted transformation behavior for both thermoelastic and nonthermoelastic systems $[7,8]$. The applicability of 


\section{Dynamics}

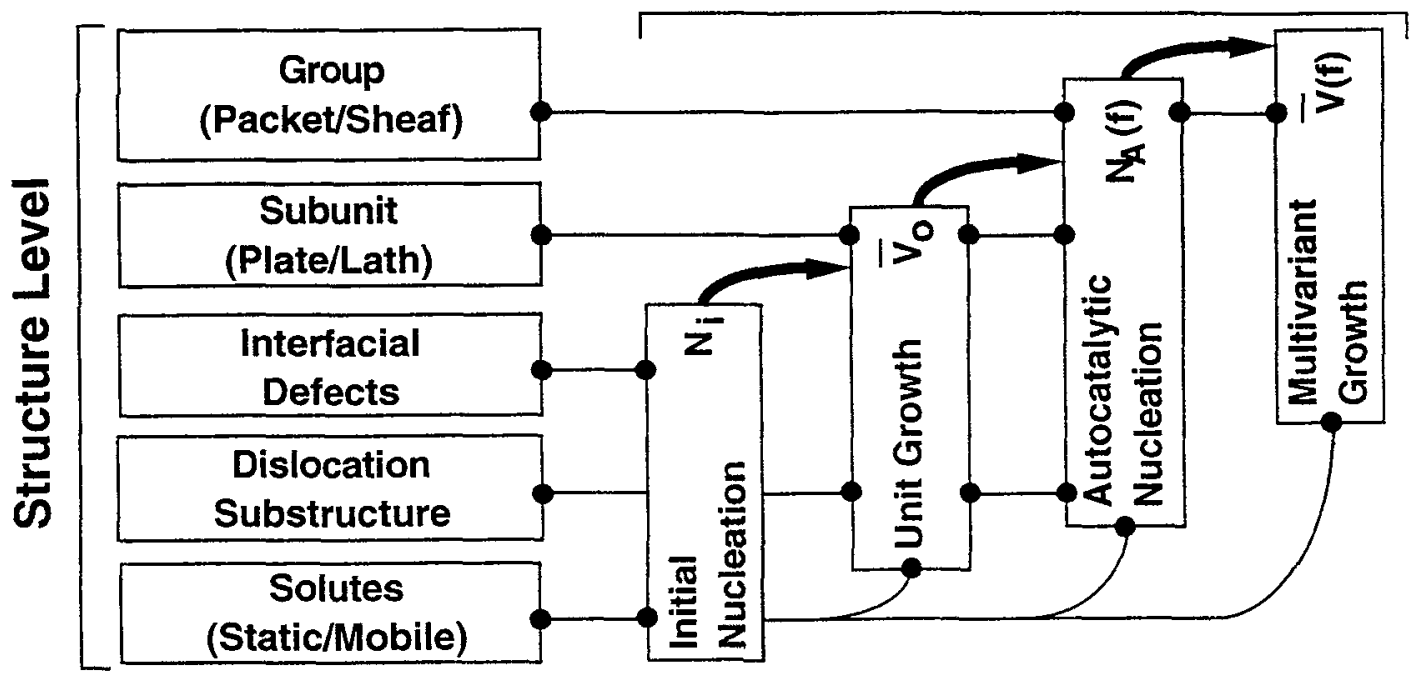

Figure 1: System diagram for dynamic stuctural hierarchy in displacive transformations.

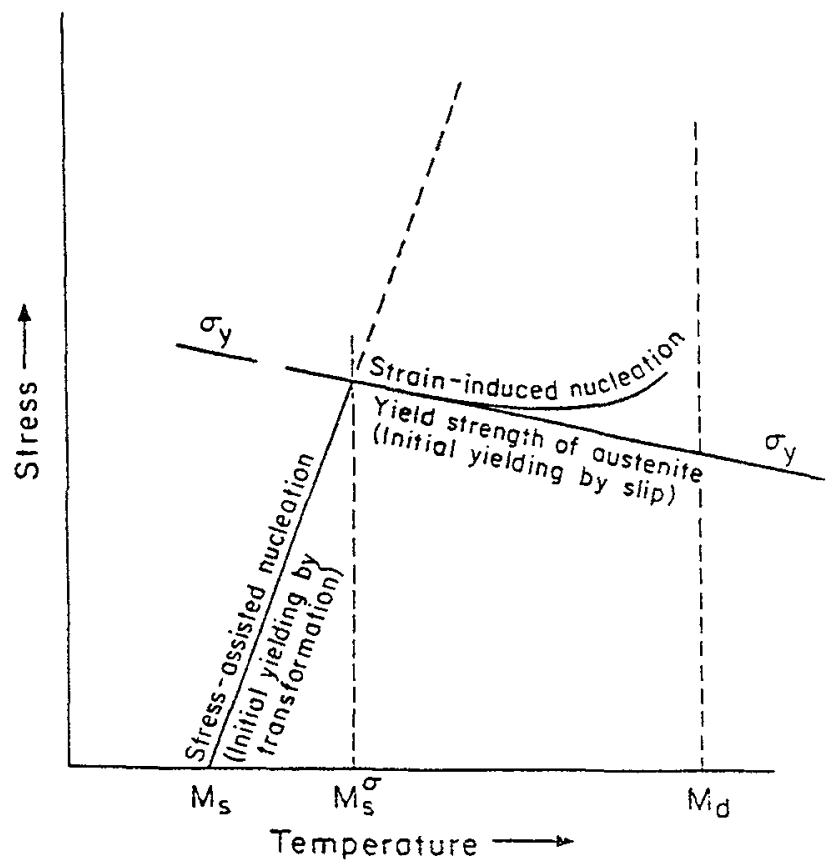

Figure 2: Stress-temperature diagram illustrating position of $\mathrm{M}_{\mathrm{s}}^{\sigma}$ temperature bounding regimes of stress-assisted and straininduced transformation [9]. 
these transformation kinetics-based constitutive models to $\mathrm{ZrO}_{2}$ ceramics has been tested by Reyes-Morel and Chen [12-14].

\subsection{Strain-Induced Transformation}

In homogeneous austenitic steels of low stacking fault energy, the kinetics of strain-induced transformation is dominated by the production of shear-band intersections which act as potent nucleation sites. This process was quantitatively modeled by Olson and Cohen [15] as also reviewed in Ref. [10]. An analytic expression is obtained which prescribes the volume fraction martensite $f$ as a function of equivalent plastic strain $\epsilon$, and its dependence on temperature and pressure as governed primarily by a nucleation site potency distribution. An extension of this approach to the kinetics of strain-induced transformation in dispersed-phase systems was developed by Kuroda [16] through analysis of literature data from experiments on the model system of small iron particles dispersed in copper single crystals.

The derivation of material constitutive relations for the strain-induced transformation regime is complicated by the simultaneous (and interactive) operation of slip and transformation as deformation mechanisms. The model of Narutani, Olson and Cohen [17] is based on critical experiments on a series of austenitic stainless steels. The experiments separated two important effects: a "static hardening" influence of the transformation product as an impediment to slip, and a "dynamic softening" influence of the transformation as a competing deformation mechanism. A three-dimensional generalization of the model has been developed by Stringfellow, Parks, and Olson [18]. An important consequence of the role of dilation in the transformation kinetics is a strongly pressure-sensitive strain hardening behavior. Recent critical experiments have confirmed predicted strain-induced martensite distributions in the gradient deformation fields of notched tensile specimens [19].

\section{TRANSFORMATION TOUGHENING}

\subsection{Brittle Solids}

The manner in which transformation dilation in the wake of a moving cleavage crack can shield the crack tip to raise the maximum $\mathrm{K}$ for crack advance in a crack growth resistance curve has been well established [20,21] using simple models for stress-assisted transformation. The approach directly accounts for half the observed transformation toughening in $\mathrm{ZrO}_{2}$ ceramics. Application of experimentally tested kineticsbased relations to a crack tip reveals that stress interaction with both the transformation shear and dilation yields a significantly larger transformation zone than previous estimates and gives a substantially higher toughening interaction. The calculated transformation toughening increment as a function of transformation zone height was found to show much improved agreement with experimental data when compared to the estimates of the simple dilation based model [14]. In units of crack extension force $G$ the transformation toughening in brittle solids scales with the square of the transformation dilation. 


\subsection{Ductile Solids}

Transformation toughening in ductile solids is complicated both by the greater complexity of the constitutive behavior of strain-induced as opposed to stress-assisted transformation, and the more complex processes of ductile fracture. The experimental study by Léal [22] of the interaction of transformation with ductility and fracture toughness is reviewed in Ref. [10]. A series of six precipitation-hardenable austenitic steels based on A286 steel were designed to have a constant $1300 \mathrm{MPa}$ yield strength, varying stability with respect to transformation, and a varying transformation volume change. The alloys also had a fairly strong temperature dependence of phase stability to allow variation of stability over wide limits. The fracture ductility and $\mathrm{J}_{\mathrm{IC}}$ toughness were found to peak at the $\mathrm{M}_{\mathrm{s}}^{\sigma}$ of their respective stress states.

A subsequent study by Young [23] reviewed in Ref. [1], involved a thorough evaluation of the transformation kinetics and constitutive relations of phosphocarbide-strengthened austenitic steels in which the transformation volume change and austenite-martensite hardness difference could both be varied. The measured enhancement of toughness and fracture ductility in these alloys was similar to that observed by Léal. In the regime of shear-instability-controlled ductile fracture, the increase in $\mathrm{J}_{\mathrm{IC}}$ toughness varies linearly with transformation zone height. Correlation of the slope of this toughening response with transformation volume change $\delta \mathrm{V} / \mathrm{V}$, and austenite-martensite hardness difference $\delta \mathrm{HV}_{\mathrm{V}}$ (influencing strain hardening) shows that, in contrast to brittle solids, the toughening behavior is more dilation sensitive, with the $\delta \mathrm{J} / \mathrm{h}$ scaling with the $3 \mathrm{rd}$ power of $\delta \mathrm{V} / \mathrm{V}$. Higher $\delta \mathrm{H}_{\mathrm{V}}$ also promotes more toughening.

The remarkable transformation toughening observed by Stavehaug [24] in a new series of $\gamma^{\prime}$ strengthened austenites is summarized in Figure 3, which plots the measured room-temperature $\mathrm{J}_{\mathrm{IC}}$ toughness vs. a thermodynamic stability parameter defined by the difference between the total acting thermodynamic driving force and its critical value at $\mathrm{M}_{s}^{\sigma}$. Similar to the results of Léal and Young, the toughening is maximum at the $\mathrm{M}_{\mathrm{s}}^{\sigma}$ condition, but in these experiments the apparent toughness enhancement over the stable austenite toughness indicated by the dashed line is significantly higher.

Sectioned crack tips of the stable austenite loaded to just beyond its $\mathrm{J}_{\mathrm{IC}}$ show that limited blunting $(\sim 20$ $\mu \mathrm{m}$ ) is followed by mixed mode fracture involving some degree of shear localization from the blunted tip. In contrast, a view in Figure 4 of the crack-tip of the maximum toughness alloy loaded beyond its $\mathrm{J}_{\mathrm{IC}}$ shows the dramatically increased length scale of fracture processes in the presence of an optimal rate of crack-tip transformation. Blunting to a much larger crack-tip opening displacement is followed by crack branching and (quasi-stable) shear localization with a large transformation zone involving interaction of the two branches. One branch ultimately evolves into a propagating mixed mode crack. As supported by model calculations to be discussed, transformation hardening ahead of the crack-tip (focused by pressure sensitivity) appears to inhibit localization in this region, forcing shear localization to follow a higher-angle path promoting branching, which in turn promotes enlargement of the transformation zone.

Quantitative modeling of the mechanics of the transformation toughening has addressed mechanisms on two length scales. As an analysis of interactions of transformation hardening and void softening induced localization at the macroscopic level, Stringfellow and Parks $[25,26]$ performed a series of model calculations incorporating a Gurson/Needleman-Tvergaard void softening model into the transformation 


\section{$\Delta 12 \% \mathrm{Cr} \bigcirc 4 \% \mathrm{Cr}$}

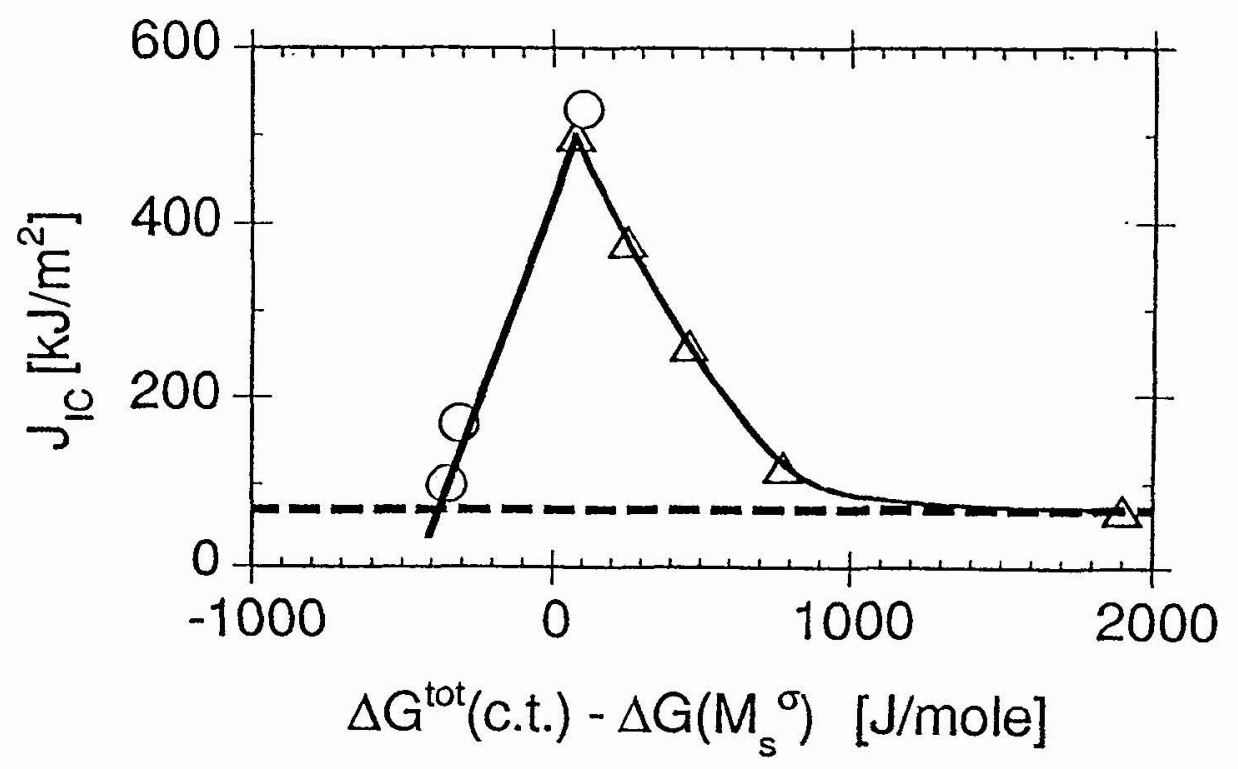

Figure 3: Measured JIC fracture toughness of $12 \mathrm{Cr}$ and $4 \mathrm{Cr}$ austenitic alloy series (1380 MPa yield strength) as a function of thermodynamic austenite stability parameter [24].

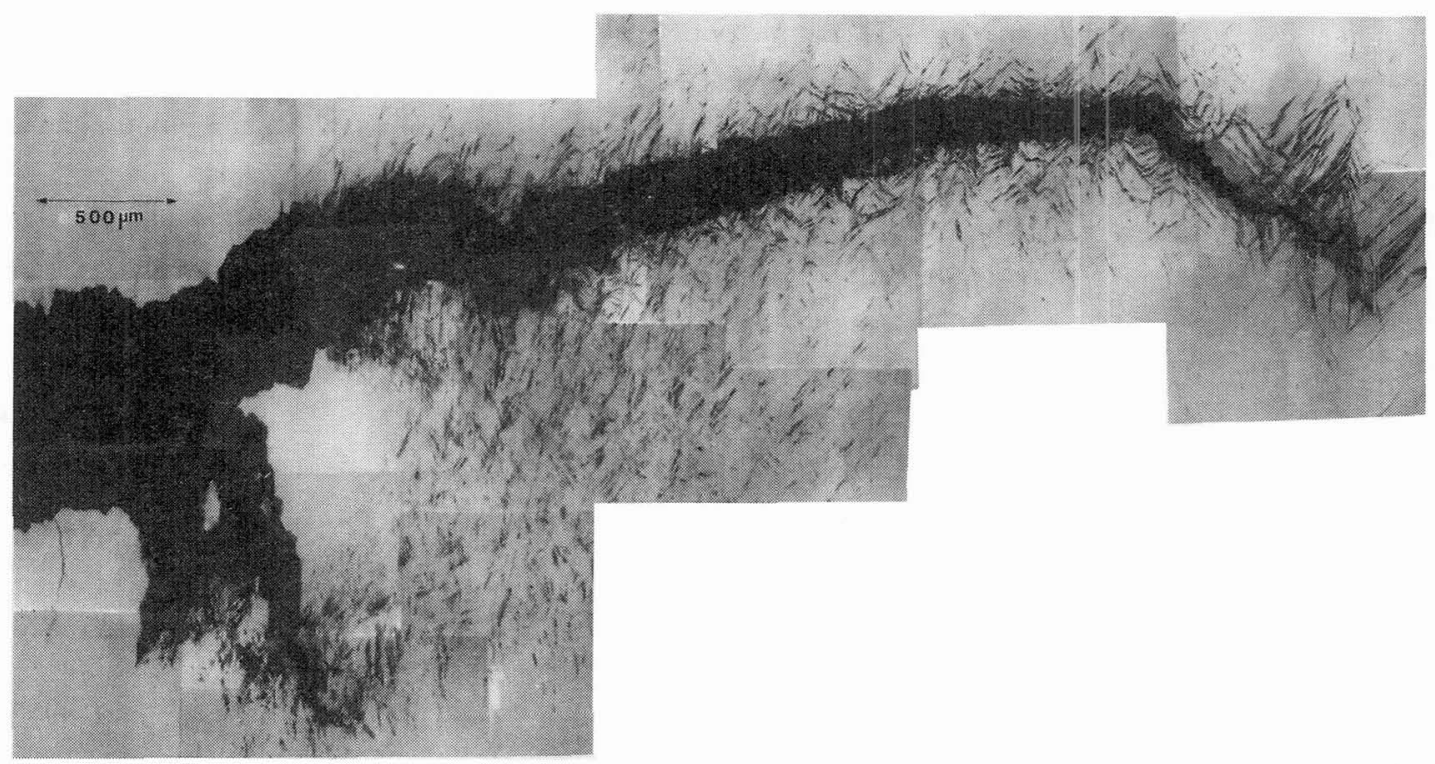

Figure 4: Sectioned crack tip region of maximum toughness $12 \mathrm{Cr}-17 \mathrm{Ni}$ austenitic alloy precipitation strengthened to 1380 MPa yield strength [24]. 
constitutive model. Figure 5 compares the evolution of equivalent shear strain $\bar{\gamma}$ and strain rate $\dot{\bar{\gamma}}$ in a plane-strain blunt-notch geometry with and without the strain-induced transformation. The $\dot{\bar{\gamma}}$ contours clearly show void-softening-induced shear localization in the non-transforming material which is strongly inhibited in the transforming material. Figure 6 compares the distribution of martensite fraction $f$ and void porosity $\rho^{*}$. As the two phenomena respond in similar ways to plastic strain and hydrostatic tension, the transformation is highly efficient in acting selectively to enhance high-strain strain hardening behavior in the regions of highest damage, thus offsetting the mechanical consequence of this damage.

On a finer length scale, electron microscopy observations [23] of the distribution of fine strain-induced martensite around $0.1 \mu \mathrm{m}$-scale particles after straining to levels beyond the microvoid nucleation strain of nontransforming material indicate a more direct cross-interaction between transformation and the unit processes of ductile fracture. Socrate and Parks [27] have applied the transformation constitutive model in numerical simulations of microvoid nucleation, growth and coalescence employing a cohesive-zone model for interface debonding similar to that introduced by Needleman [28]. Using interfacial strength estimates for the TiC particles observed in the experimental alloys, Figure 7 Shows the normalized interfacial opening separation as a function of angular position around a particle during microvoid nucleation with increasing applied strain levels at a remote stress state of $\sigma_{h} / \bar{\sigma}=1.12$. Comparing the transforming and nontransforming behaviors, transformation delays the onset of microvoid nucleation and reduces the degree of debonding for a given applied strain. Computed transformation fields prior to nucleation are in good agreement with the experimental observations. Simulations of interacting pairs of particles also demonstrate retardation of microvoid coalescence, but the largest toughening effect appears to be associated with delay of the shear instability driven by void growth softening, as captured in the simpler model of Figure 5.

Continued experimental investigation of the toughening behavior of these alloys by Bergstrom [19] demonstrates the role of a third length scale as represented by the crack branching phenomenon of Figure 4. The higher constraint of side-grooved compact tension specimens of greater thickness diminishes the branching and shows that this effect contributes a significant fraction of the toughening increment of Figure 3. In the absence of the transformation-enhanced branching which greatly increases the fracture process zone size, the observed transformation toughening is of the order of a factor of 2 , similar to the earlier measurements of Léal [22] and Young [23].

While the experiments in model austenitic alloys provide insights into the fundamental mechanisms of transformation toughening in ductile solids, the greatest practical need for exploitation of this phenomenon is in ultrahigh-strength martensitic steels where similar mechanical behavior can be achieved with dispersions of metastable austenite particles. In such systems, critical experiments employing cryogenic high magnetic field (20 Tesla) treatments to vary retained austenite content in otherwise identical microstructures [29] demonstrate that retained austenite in Stage I (200C) tempered 4340 martensitic steel is of optimal stability for enhancement of shear instability resistance in torsion, but insufficient stability for enhancement of $\mathrm{K}_{\mathrm{IC}}$ toughness. The higher austenite stability levels needed for toughening can be achieved in high-Ni secondary hardening steels where substitutional diffusion at high tempering temperatures allows precipitation of Ni-enriched austenite. Achieving fine particle sizes further enhances stability though the statistical behavior of heterogeneous martensitic nucleation [5-7]. Guided by 

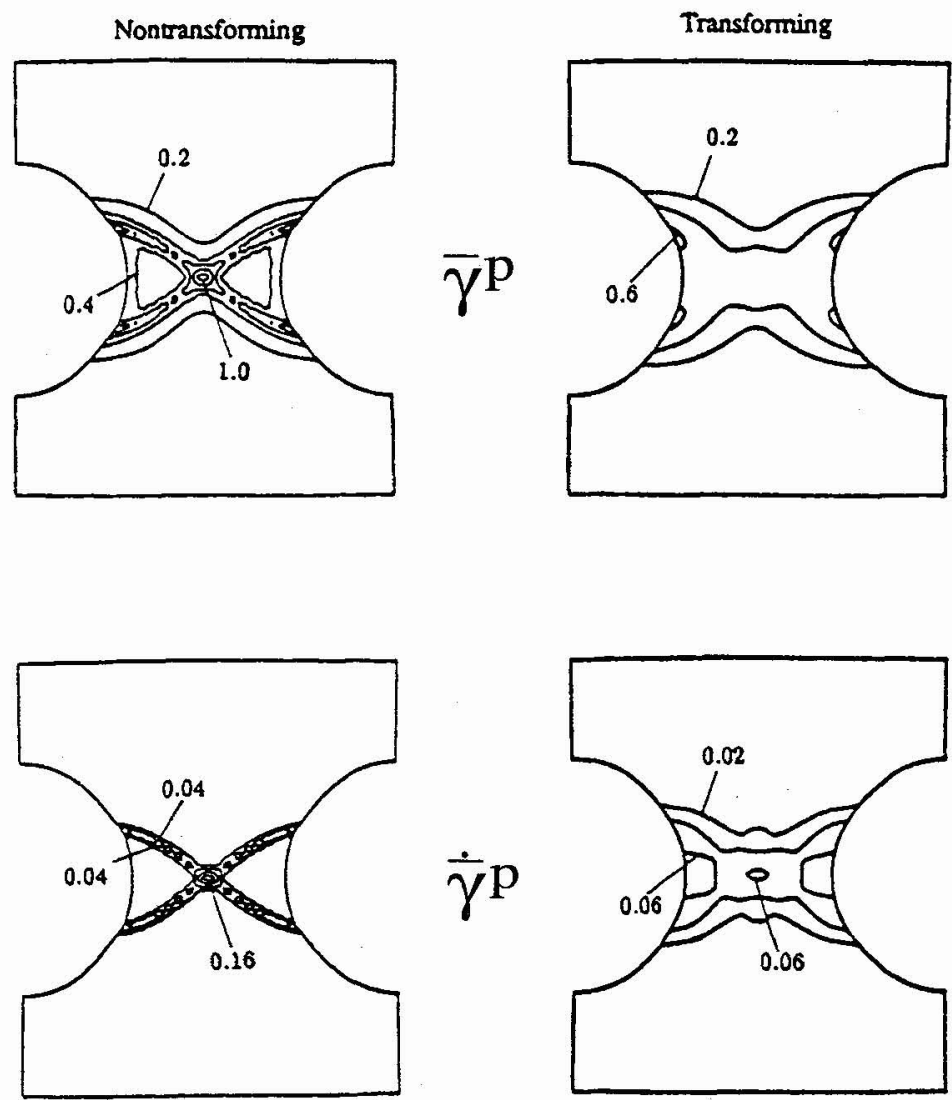

Figure 5: Computed deformation of plane-strain blunt-notch geometry of nontransforming (left) and transforming (right) material showing contours of plastic strain $\bar{\gamma}^{p}$ and plastic strain rate $\dot{\gamma}^{p}[26]$.

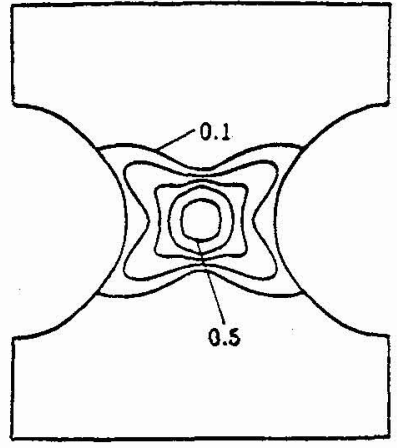

$f$

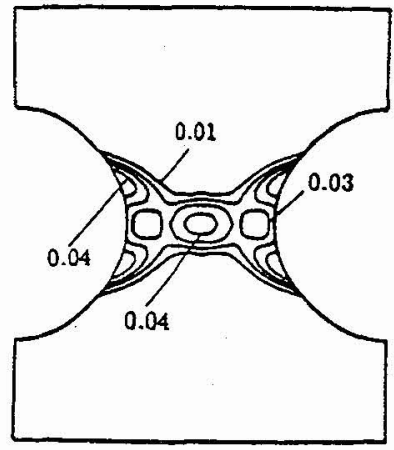

$\rho^{*}$

Figure 6: Contours of martensite fraction $f$ and microvoid density $p^{*}$ for transforming material of Figure 5 [26]. 


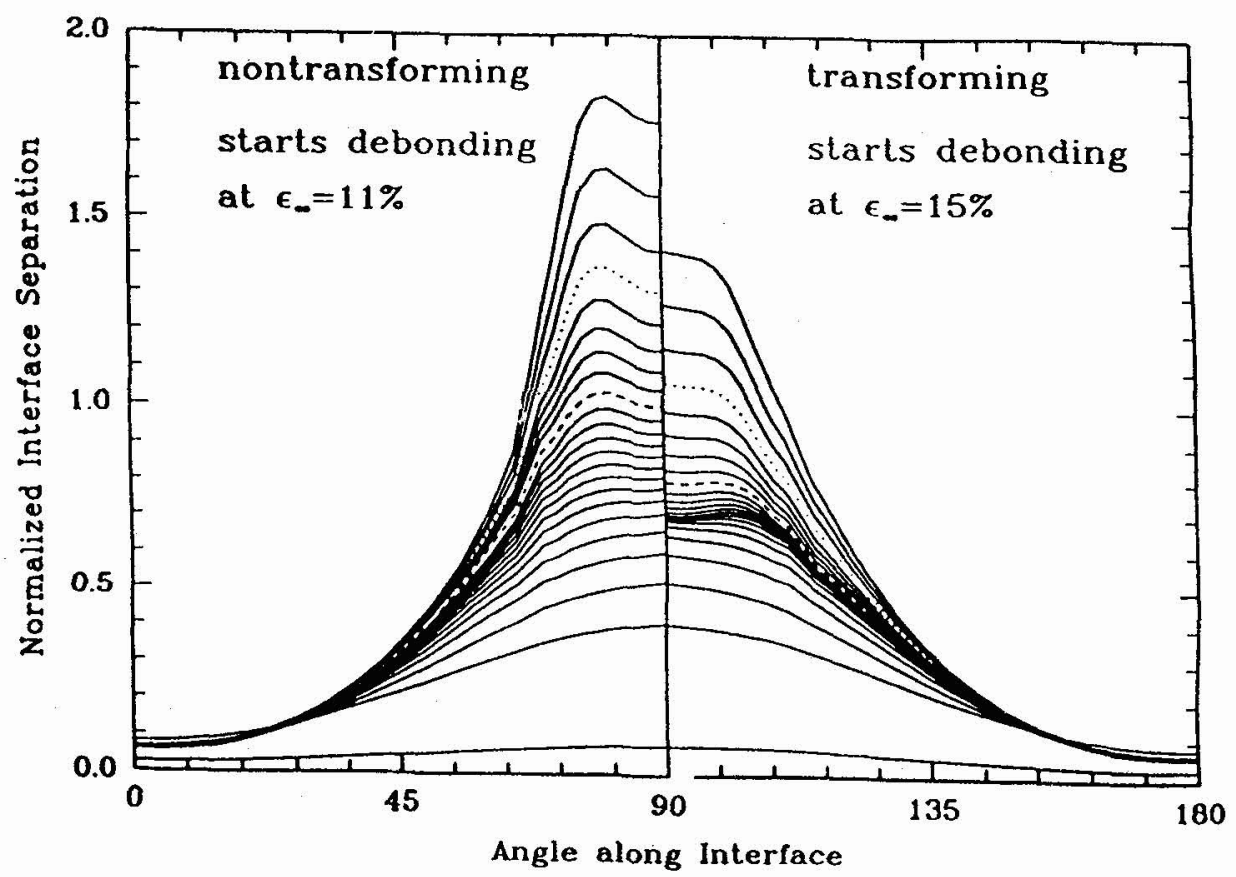

Figure 7: Computed interfacial opening separation (normalized to interfacial interaction range $\delta_{n}$ ) as a function of angular position $\phi$ from the radial direction for spherical particle in transforming and nontransforming matrices at increasing loads of applied axial strain [27].

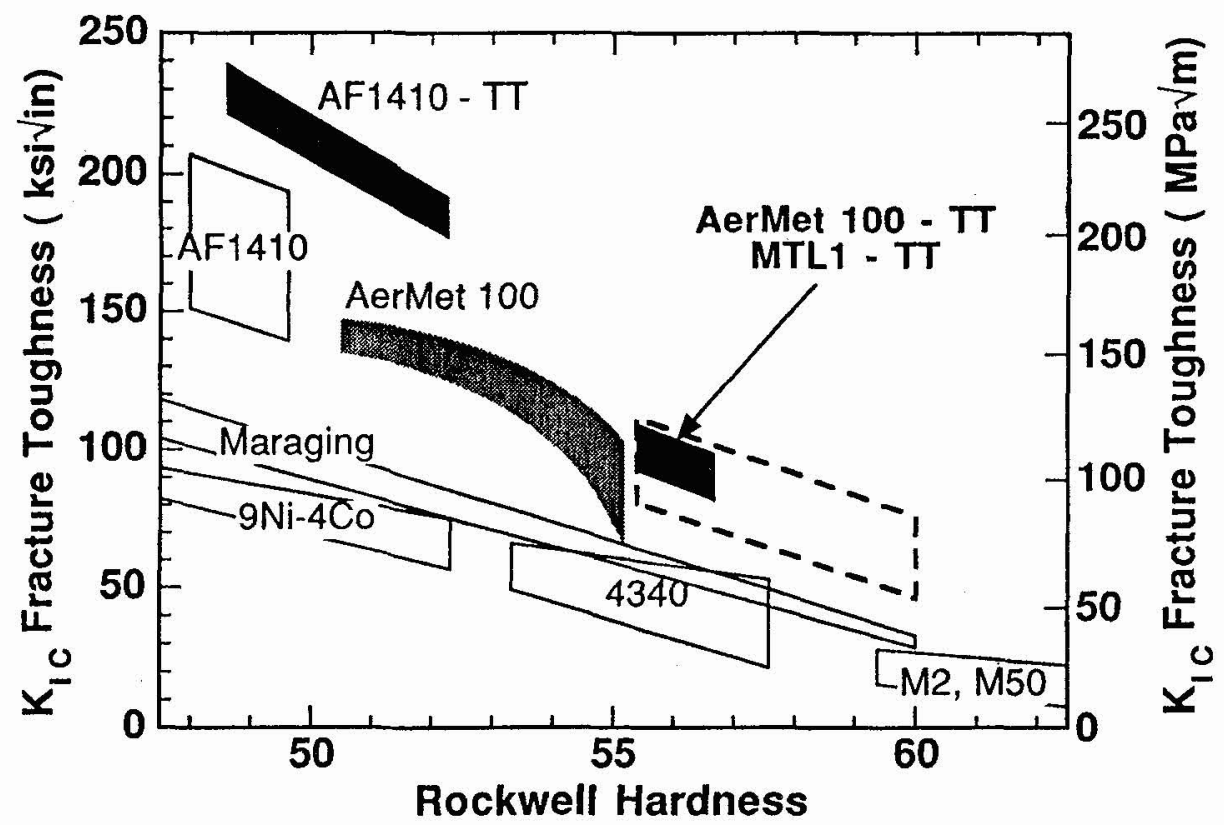

Figure 8: Cross-plot of $\mathrm{KIC}$ fracture toughness and Rockwell C hardness illustrating improved properties of transformation toughened (TT) alloys [30-32]. 
thermodynamic predictions, multistep tempering treatments have been developed to achieve such dispersions on a $\sim 10 \mathrm{~nm}$ size scale in the commercial AF1410 alloy steel [30]. The AF1410-TT band of Figure 8 illustrates the toughness-hardness combinations thus achieved by transformation toughening in comparison with current alloys. More recently, similar treatments have been developed to achieve similar property gains in the new higher strength Aermet 100 alloy as well as a prototype armor steel designated MTL1 [31,32]; as denoted in Figure 8 the transformation toughened forms of these alloys have achieved properties within the dashed box corresponding to the objectives of the multi-institutional Steel Research Group program [1].

\section{CONCLUSIONS}

Quantitative analysis of the dynamic evolution of multilevel structure during martensitic transformations has provided the foundation for kinetics-based constitutive relations for transformation plasticity during both the stress-assisted and strain-induced modes of mechanically induced transformation. Application in numerical modeling of ductile fracture by microvoid-softening-induced shear localization, in conjunction with metallographic observation of crack-tip transformation and localization processes, reveals transformation toughening processes operating on three structural length scales, generally associated with the flow stabilizing influence of pressure-sensitive strain hardening provided by strain-induced transformation. Application of the phenomena via dispersed-phase transformation plasticity in ultrahighstrength martensitic steels has demonstrated record toughness levels in both commercial and experimental alloy steels.

\section{Acknowledgments}

Research in transformation toughening at Northwestern in collaboration with Prof. D. M. Parks of MIT is performed under DOE Grant DE-FG02-88ER45365. Research on transformation mechanisms is supported by NSF Grant DMR-9500122, and research on dispersed-phase transformation toughening is supported by ARO Grant DAAH04-93-G-0471.

\section{References}

[1] Olson G.B., "Science of Steel", in Innovations in Ultrahigh-Strength Steel Technology, 34th Sagamore Army Materials Research Conference Proceedings, G.B. Olson, M. Azrin, and E.S. Wright Eds., (U.S. Government Printing Office, 1990) pp. 3-58.

[2] Olson G.B., J. Materials Ed. 11 (1989) 515-528.

[3] Olson G.B. "Materials Design: An Undergraduate Course", Morris E. Fine Symposium, P.K. Liaw, J.R. Weertman, H.L. Marcus, and J.S. Santner Eds., (TMS-AIME, Warrendale PA, 1991) pp. 41-48.

[4] Smith C.S., A Search for Structure (MIT, 1988).

[5] Olson G.B. and Cohen M., Dislocations in Solids Vol. 7, F.R.N. Nabarro Ed. (North-Holland, 1986) pp. 295-407.

[6] Chen I-W., Chiao Y-H., and Tsuzaki K., Acta Metall. 33 (1985) 1847-1859. 
[7] Lin M., Olson G.B., and Cohen M., Metall. Trans. 23A (1992) 2987-98.

[8] Olson G.B. and Ohtsuka H., "Kinetics of Thermoelastic Martensitic Transformations", International Symposium on Shape Memory Materials, Beijing 25-28 September 1994, Y. Chu and H. Tu Eds. (International Academic Publishers, Beijing, 1994) pp. 17-23.

[9] Olson G.B. and Cohen M., J. Less-Common Metals (1972) 107-118.

[10] Olson G.B. and Cohen M., Mechanical Properties and Phase Transformations in Engineering Materials, S.D. Antalovich, R.O. Ritchie, and W.W. Gerberich Eds. (TMS-AIME, 1986) pp. 367-390.

[11] Olson G.B. Tsuzaki K., and Cohen M., "Statistical Aspects of Martensitic Nucleation", Turnbull Symposium: Phase Transitions in Condensed Systems, G.S. Cargill, F. Spaepen, and K.N. Tu Eds. (MRS, 1987) pp. 129-148.

[12] Chen I-W. and Reyes-Morel P.E., J. Amer. Ceram. Soc. 69 (1986) 181-189.

[13] Chen I-W., J. Amer. Ceram. Soc. 69 (1986) 189-194.

[14] Reyes-Morel P.E., "An Experimental Study of Constitutive Relations of Transformation Plasticity in Zirconia-Based Ceramics" (Ph.D. Thesis, MIT) June 1986.

[15] Olson G.B. and Cohen M., Metall Trans A 6A (1975) 791.

[16] Kuroda Y., "Kinetics of Deformation-Induced Transformation of Dispersed Austenite in Two Alloy Systems" (M.S. Thesis, MIT) June 1987.

[17] Narutani T., Olson G.B., and Cohen M., J. de Physique 43 (1982) C4-429 - 434.

[18] Stringfellow R.G., Parks D.M., and Olson G.B., Acta Metall. 40 (1992) 1703-1716.

[19] Bergstrom D., doctoral research in progress, Northwestern University.

[20] Budiansky B., Hutchinson J.W., and Lambropoulos J.C., Int. J. Solids and Structures 19 (1983) 337355 .

[21] McMeeking R. and Evans A.G., J. Amer. Ceram Soc. 65 (1982) 242-245.

[22] Léal R., "Transformation Toughening of Metastable Austenitic Steels" (Ph.D. Thesis, MIT) June 1984.

[23] Young C-C., "Transformation Toughening in Phosphocarbide-Strengthened Austenitic Steels" (Ph.D. Thesis, MIT) June 1988.

[24] Stavehaug F., "Transformation Toughening of $\gamma$ ' Strengthened Metastable Austenitic Steels" (Ph.D. Thesis, MIT) November 1990.

[25] Stringfellow R. and Parks D.M., "Strain-Induced Transformation Toughening in Metastable Austenitic Steels", Int. J. Plasticity 7 (1991) 529.

[26] Stringfellow R., "Mechanics of Strain-Induced Transformation Toughening in Metastable Austenitic Steels" (Ph.D. Thesis, MIT) November 1990.

[27] Socrate S., Ph.D. Thesis, MIT, June 1995.

[28] Needleman A., J. Appl.Mech. 54 (1987) 525.

[29] Haidemenopoulos G.N., Olson G.B., Cohen M., and Tsuzaki K., Scripta Metall. 23 (1989) 207-212. 
[30] Haidemenopoulos G.N., Olson G.B., and Cohen M., "Dispersed-Phase Transformation Toughening in Ultrahigh-Strength Steels", in Innovations in Ultrahigh-Strength Steel Technology, 34th Sagamore Army Materials Research Conference Proceedings, G.B. Olson, M. Azrin, and E.S. Wright Eds., (U.S. Government Printing Office, Washington DC, 1990) pp. 549-593.

[31] Kuehmann D.J., Cho J., Stephenson T.A., and Olson G.B., "Systems Design of High Performance Steels", Metallic Materials for Lightweight Applications, 40th Sagamore Army Materials Research Conference, Plymouth MA, (U.S. Army Research Laboratory - Materials Directorate, 1993) 337-355.

[32]Srinivas M., Kuehmann C.J., and Olson G.B., manuscript in preparation. 